\title{
Association between subclinical hypothyroidism and dyslipidemia in the obesity population
}

\author{
Pedro Alarcón-González ${ }^{1}$, Jessica G. Sosa-López ${ }^{1}$, Virginia H. Sánchez-Hernández ${ }^{1 *}$, \\ Antonio Cruz-Estrada', Claudia A. Aguilar-Serralde², and Adolfo A. Velasco-Medina ${ }^{2}$ \\ ${ }^{1}$ Department of Internal Medicine; ${ }^{2}$ Clínica de Atención Integral al paciente con Diabetes y Obesidad (CAIDO). Hospital General de México "Dr. \\ Eduardo Liceaga", Mexico City, Mexico
}

\begin{abstract}
Introduction: Subclinical hypothyroidism (SCH) is defined as the increase in thyroid-stimulating hormone (TSH) levels, with triiodothyronine (T3) and tetraiodothyronine (T4) values within the population reference range. The prevalence in patients with obesity varies between $10.5 \%$ and $25 \%$. This has been related to alterations in serum concentrations of total cholesterol (TC), LDL cholesterol (LDL-C), HDL cholesterol (HDL-C), and triglycerides (TG). Objective: The objective of the study was to identify the association between SCH and dyslipidemia in patients with obesity. Materials and methods: A case-control study was carried out in 128 patients with obesity and SCH, assessed at the Clinic for Comprehensive Care of patients with Diabetes and Obesity (CAIDO) from 2015 to 2019. The Mantel-Haenszel Chi-Square Test was used to verify the association between SCH and dyslipidemias (hypertriglyceridemia, total hypercholesterolemia, LDL hypercholesterolemia, and HDL hypocholesterolemia). Odds ratio of the different dyslipidemias was calculated for the group of patients with SCH and obesity, using logistic regression models, adjusted for possible confounding factors (age, sex, and BMI). Results: Dyslipidemias were identified in $96.1 \%$ of the patients with SCH compared to $87.3 \%$ in relation to the control group (OR 3.56. 95\% Cl $=1.29-9.84$, $p=0.01$ ), the most frequent being HDL hypocholesterolemia, and hypertriglyceridemia. Conclusion: The relationship between SCH and dyslipidemia has been analyzed with controversial results at an international level. In the Mexican population with obesity, $\mathrm{SCH}$ is deemed a risk factor for the development of dyslipidemia.
\end{abstract}

Key words: Hypothyroidism. Obesity. Dyslipidemia.

\section{Introduction}

Subclinical hypothyroidism ( $\mathrm{SCH}$ ) is defined as the state of increased serum thyroid-stimulating hormone (TSH), with concentrations of Tetraiodothyronine (T4) and Triiodothyronine (T3) within the population reference range. The upper normal limit of TSH depends on the study population, with $4.0 \mathrm{mU} / \mathrm{L}$ being the standard reference parameter ${ }^{1}$. The incidence of $\mathrm{SCH}$ varies between $4 \%$ and $10 \%$ depending on sex, age, and population studied 2,3 . It has been reported that elevated serum TSH concentrations are found in morbidly obese euthyroid patients, with lower levels of anti-TPO antibodies; suggesting that the increase in TSH, especially in morbidly obese patients, could be caused by mechanisms unrelated to the thyroid function ${ }^{4}$.

The lack of evidence of autoimmunity in this group of patients is consistent with the explanation that the increase in TSH is a response mechanism against weight gain, capable of counteracting the accumulation of fat

\section{Correspondence:}

*Virginia H. Sánchez-Hernández

E-mail: vickysanmd@yahoo.com NC-ND license (http://creativecommons.org/licenses/by-nc-nd/4.0/).
Available online: 22-01-2021

Rev Med Hosp Gen Mex. 2021;84(1):11-17 www.hospitalgeneral.mx 
due to increased energy expenditure ${ }^{5}$. In addition, there is a condition of peripheral thyroid hormone resistance because TSH receptors are expressed in smaller quantities in the adipocytes of obese individuals ${ }^{6}$.

The prevalence of $\mathrm{SCH}$ ranges between $10.5 \%$ and $25 \%$ in patients with obesity and is higher than in the general population ${ }^{7,8}$. Montoya et al. conducted a prospective, observational, cross-sectional, descriptive study from 2009 to 2011, and demonstrated a prevalence of $\mathrm{SCH}$ of $6 \%$ in Mexican patients with obesity ${ }^{9}$.

In relation to the pathogenesis of dyslipidemia, there are several mechanisms related to lipid metabolism in $\mathrm{SCH}$. Thyroid hormones act as inducers of hydroxymethylglutaryl coenzyme A (HMG-CoA) reductase, increasing liver cholesterol synthesis. There is overexpression of membrane receptors of low-density lipoprotein cholesterol (LDL-C) in the hepatocytes, fibroblasts and other tissues; generating decrease in LDL-C clearance. Cholesterol ester transfer protein (CETP) is decreased; being negatively related to the transfer of high-density lipoprotein cholesterol (HDL-C) to very low-density lipoprotein cholesterol (C-VLDL) and low-density lipoprotein cholesterol (LDL-C). Finally, thyroid hormones stimulate the flow of cholesterol through transporter ABCA1 from macrophages to $\mathrm{HDL}-\mathrm{C}^{10}$. In patients with obesity, the physiopathology of dyslipidemia includes liver overproduction of C-VLDL, decreased triglyceride (TG) lipolysis, and altered peripheral uptake of free fatty acids, as well as increased flows of free-fatty acids from adipocytes to the liver, other tissues, and formation of LDL-C. Hence, both $\mathrm{SCH}$ and obesity are determining factors for the development of dyslipidaemia ${ }^{11}$.

Obesity is a global health issue. In Mexico, it represents an important public health problem since according to ENSANUT 2018; the percentage of adults aged 20 years or older that are overweight and obese is $75.2 \%$ (39.1\% overweight and $36.1 \%$ obese). In 2012 , this percentage was $71.3 \% \%^{12}$. Obesity is related to various endocrine disorders, including thyroid hormone disorders, concomitant with the hypermetabolic, and pro-inflammatory state presented by this population.

The international literature has related a greater prevalence of $\mathrm{SCH}$ in obesity, a thyroid state that, in turn, has been related to inconsistencies in relation to the lipid profile. At present, there are few descriptions of the characteristics of lipid levels, in patients with obesity with $\mathrm{SCH}$ in Mexican population, Therefore, the aim of this study was to identify the association between $\mathrm{SCH}$ and dyslipidemias (total hypercholesterolemia, LDL hypercholesterolemia, HDL hypercholesterolemia, and hypertriglyceridemia) in obese patients, as well as to evaluate the odds ratio (OR) for their development.

\section{Materials and methods}

A case-control study was carried out in patients aged 18-59 years assessed at the Comprehensive Care Clinic for patients with Diabetes and Obesity at the General Hospital of Mexico "Dr Eduardo Liceaga," from 2015 to 2019. Those patients met the criteria for obesity according to body mass index (BMl; $\mathrm{kg} / \mathrm{m} 2)$, Obesity Grade I; 30-34.9 BMI, Obesity Grade II; 3539.9 BMI, and Obesity Grade III; $\geq 40 \mathrm{BMI}$, according to the American Association of Clinical Endocrinologists (AACE) $2016^{13}$.

Cases (128) were determined in obese patients who met SCH criteria with TSH determination $\geq 4.0 \mathrm{mU} / \mathrm{L}$ of the standard reference parameter according to the European Thyroid Association (ETA) 2013', and who had serum TC, LDL-C, HDL-C, and TG measurements.

Obese and euthyroid patients with serum TC, LDL-C, HDL-C, and TG measurements were determined as control (150). Those patients with thyroid hormone levels within the population reference ranges; TSH 0.38-4 mU/L, T3L 2.39-6.79 mU/L, and T4L 0.58$1.64 \mathrm{mU} / \mathrm{L}$ were considered euthyroid.

The study excluded patients diagnosed with type 2 diabetes mellitus, other types of thyroid disease, patients that had been prescribed any drug for altered thyroid function (lithium, amiodarone, iodide, carbamazepine, rifampicin, phenobarbital, and glucocorticoids) and patients with any autoimmune disease (Lupus and rheumatoid arthritis).

In both groups, measurements of age, weight, height, BMI, serum thyroid hormone levels, serum TC, LDL-C, HDL-C, and TG concentrations were obtained. The prevalence of the different dyslipidemias was determined.

Dyslipidemia was defined as any of the following alterations in the lipid profile: TC $>200 \mathrm{mg} / \mathrm{dl}$, LDL-C > $100 \mathrm{mg} / \mathrm{dl}, \mathrm{HDL}-\mathrm{C}<50 \mathrm{mg} / \mathrm{dl}$ for men, HDL-C $<40 \mathrm{mg} / \mathrm{dl}$ for women, and TG > $150 \mathrm{mg} / \mathrm{dl}$.

SPSS software version 22 for Windows was used for statistical analysis. Descriptive statistics (proportions, mean, and standard deviation) were used for the following variables: age, weight, height, BMI, serum thyroid hormone levels, serum TC, LDL-C, HDL-C, and TG concentrations.

The Shapiro-Wilk test was used as a test of normality. Comparisons of the different variables between cases and controls were made, using Student's t-test for independent data, and in cases where the distribution 
Table 1. Characteristics of the study population: Patients with subclinical hypothyroidism and euthyroid patients

\begin{tabular}{|c|c|c|c|c|}
\hline & & $\begin{array}{l}\text { Patients with obesity and } \\
\text { subclinical hypothyroidism }(n=128)\end{array}$ & $\begin{array}{l}\text { Euthyroid obese patients } \\
\qquad(n=150)\end{array}$ & p value \\
\hline & Total mean & Mean & Mean & \\
\hline Age (years) & $44.33 \pm 11.91$ & $45.50 \pm 11.69$ & $43.28 \pm 12.04$ & 0.12 \\
\hline Weight (kg) & $110.80 \pm 26.57$ & $109.02 \pm 25.61$ & $112.32 \pm 27.35$ & 0.33 \\
\hline Height (m) & $1.58 \pm 0.90$ & $1.56 \pm 0.08$ & $1.60 \pm 0.09$ & 0.001 \\
\hline BMI $\left(\mathrm{kg} / \mathrm{m}^{2}\right)$ & $43.70 \pm 8.31$ & $44.11 \pm 8.10$ & $43.34 \pm 8.49$ & 0.44 \\
\hline TSH & $4.14 \pm 2.77$ & $6.15 \pm 2.87$ & $2.43 \pm 0.88$ & $\leq 0.001$ \\
\hline T3L & $3.25 \pm 0.49$ & $3.30 \pm 0.48$ & $3.20 \pm 0.49$ & 0.082 \\
\hline ТЗТ & $1.41 \pm 1.34$ & $1.68 \pm 1.86$ & $1.27 \pm 0.98$ & 0.006 \\
\hline T4L & $0.88 \pm 0.15$ & $0.86 \pm 0.14$ & $0.90 \pm 0.15$ & 0.021 \\
\hline T4T & $8.31 \pm 1.86$ & $8.20 \pm 1.79$ & $8.36 \pm 1.90$ & 0.57 \\
\hline Total Cholesterol & $185.05 \pm 42.09$ & $189.32 \pm 44.29$ & $181.41 \pm 39.9$ & 0.11 \\
\hline LDL cholesterol & $111.61 \pm 33.64$ & 115.8297 & $108.02 \pm 33.7$ & $\leq 0.03$ \\
\hline HDL cholesterol & $42.16 \pm 11.43$ & $40.72 \pm 10.19$ & $43.40 \pm 12.29$ & $\leq 0.05$ \\
\hline Triglycerides & $166.41 \pm 77.03$ & $173.99 \pm 78.44$ & $159.95 \pm 75.47$ & 0.043 \\
\hline Diagnosis of dyslipidemia $\mathrm{n}(\%)$ & 254 & $123(96.1 \%)$ & $131(87.3 \%)$ & 0.01 \\
\hline Total hypercholesterolemia & 87 & $46(35.9 \%)$ & $41(27.3 \%)$ & 0.123 \\
\hline LDL hypercholesterolemia & 168 & $83(64.8 \%)$ & $85(56.7 \%)$ & 0.165 \\
\hline HDL Hypocholesterolemia & 206 & $105(82 \%)$ & $101(67.3 \%)$ & 0.005 \\
\hline Hypertriglyceridemia & 134 & $70(54.7 \%)$ & $64(42.7 \%)$ & 0.046 \\
\hline
\end{tabular}

BMI: Body mass index; HDL: High-density lipoprotein; kg: Kilograms; m: Meters; LDL: Low-density lipoprotein; TSH: Thyroid-stimulating hormone; T3L: Free triiodothyronine; T3T: Total triiodothyronine; T4L: Free tetraiodothyronine; T4T: Total tetraiodothyronine.

of results was not homogeneous, the Mann-Whitney U-test was applied as a nonparametric test of the null hypothesis.

To contrast the hypothesis of association between $\mathrm{SCH}$ and the presence of dyslipidemias, the Mantel-Haenszel Chi-square test was used. All hypothesis contrast tests with $p<0.05$ were deemed statistically significant.

Odds ratios of the different dyslipidemias were calculated for the group of patients with $\mathrm{SCH}$ and obesity. The odds ratio (OR) and the respective $95 \%$ confidence intervals $(\mathrm{Cl})$ were calculated by means of logistic regression models and then adjusted for possible confounding factors (age, sex, and BMI).

The OR of the dyslipidemia variable was calculated and the respective $95 \%$ Cls were calculated by logistic regression. Comparisons were adjusted for sex, age (under 35 years vs. over 35 years), BMI (under $40 \mathrm{~kg} / \mathrm{m}^{2}$ vs. over $40 \mathrm{~kg} / \mathrm{m}^{2}$ ), and $\mathrm{SCH}$ (presence or absence).

\section{Results}

Out of a sample of 1118 potentially eligible subjects, 278 subjects meeting the inclusion criteria were analyzed.

In total, 227 female patients and 51 male patients were analyzed, corresponding to $81.7 \%$ and $18.3 \%$ of the population, respectively. Comparisons of population characteristics show that there is no difference in age, weight, and BMI in the group of euthyroid patients in relation to those diagnosed with $\mathrm{SCH}$ (Table 1).

When the population characteristics categorized according to sex were compared, only a statistically significant difference was found in weight, height, and BMI. These values were higher in male patients (Table 2).

According to obesity grades, $13.3 \%(n=37)$ were classified as obesity Grade $1 ; 22.3 \%(n=62)$, as obesity Grade 2, and $64.4 \%(n=179)$ as obesity Grade 3.

Patients with $\mathrm{SCH}$ showed a higher prevalence of dyslipidemia, $96.1 \%$ versus $87.3 \%$, in relation to the control group (3.56. 95\% Cl $=1.29-9.84, p=0.01$ ). 
Table 2. Characteristics of the study population, according to the sex of the patients

\begin{tabular}{|c|c|c|c|c|}
\hline Characteristics & Males $(n=51) 18.3 \%$ & Females $(n=227) 81.7 \%$ & Total (278) & p value \\
\hline Patient's age (years) & $41.75 \pm 10.73$ & $44.88 \pm 12.11$ & $44.33 \pm 11.91$ & 0.090 \\
\hline Weight (kg) & $131.17 \pm 30.96$ & $106.22 \pm 23.20$ & $110.80 \pm 26.57$ & $<0.0001$ \\
\hline Height (m) & $1.68 \pm 0.08$ & $1.56 \pm 0.07$ & $1.58 \pm 0.90$ & $<0.0001$ \\
\hline Body mass index $\left(\mathrm{kg} / \mathrm{m}^{2}\right)$ & $45.79 \pm 8.61$ & $43.23 \pm 8.19$ & $43.70 \pm 8.31$ & 0.047 \\
\hline TSH levels (mU/L) & $3.75 \pm 2.50$ & $4.23 \pm 2.82$ & $4.14 \pm 2.77$ & 0.268 \\
\hline Free T3 levels (mU/L) & $3.34 \pm 0.60$ & $3.23 \pm 0.46$ & $3.25 \pm 0.49$ & 0.136 \\
\hline Total T3 levels (mU/L) & $1.60 \pm 1.83$ & $1.36 \pm 1.20$ & $1.41 \pm 1.34$ & 0.348 \\
\hline Free T4 levels (mU/L) & $0.89 \pm 0.13$ & $0.88 \pm 0.16$ & $0.88 \pm 0.15$ & 0.717 \\
\hline Total T4 levels (mU/L) & $8.02 \pm 2.41$ & $8.38 \pm 1.71$ & $8.31 \pm 1.86$ & 0.308 \\
\hline Total Cholesterol & $179.59 \pm 43.01$ & $186.29 \pm 41.87$ & $185.05 \pm 42.09$ & 0.302 \\
\hline LDL cholesterol & $109.50 \pm 33.80$ & $112.08 \pm 33.66$ & $111.61 \pm 33.64$ & 0.621 \\
\hline HDL Cholesterol & $38.13 \pm 9.26$ & $43.07 \pm 11.69$ & $42.16 \pm 11.43$ & 0.500 \\
\hline Triglycerides & $176.90 \pm 83.29$ & $164.06 \pm 75.55$ & $166.41 \pm 77.03$ & 0.283 \\
\hline Diagnosis of dyslipidemia $n(\%)$ & $47(92.2 \%)$ & $207(91.2 \%)$ & 254 & 0.541 \\
\hline Total hypercholesterolemia & $13(25.5 \%)$ & $74(32.6 \%)$ & 87 & 0.207 \\
\hline LDL hypercholesterolemia & $33(64.7 \%)$ & $135(59.5 \%)$ & 168 & 0.299 \\
\hline HDL hypocholesterolemia & $33(64.7 \%)$ & $173(36.2 \%)$ & 206 & 0.067 \\
\hline Hypertriglyceridemia & $29(56.8 \%)$ & $105(46.2 \%)$ & 134 & 0.112 \\
\hline
\end{tabular}

BMI: Body mass index; HDL: High-density lipoprotein; kg: Kilograms; m: Meters; LDL: Low-density lipoprotein; TSH: Thyroid-stimulating hormone; T3L: Free triiodothyronine; T3T: Total triiodothyronine; T4L: Free tetraiodothyronine; T4T: Total tetraiodothyronine.

Regarding the specific prevalence for each dyslipidemia, a significant difference was observed for HDL hypocholesterolemia. It was higher for the group of patients with $\mathrm{SCH}, 82 \%$ versus $67.3 \%$, in euthyroid patients (2. 21. $95 \% \mathrm{Cl}=1.25-3.9, \mathrm{p}=0.006)$. A significant difference was also observed for hypertriglyceridemia, $54.7 \%$ in patients with $\mathrm{SCH}$ versus $42.7 \%$ in the euthyroid population $(1.62 .95 \% \mathrm{Cl}=1.008-2.60$, $p=0.046$ ).

No significant difference was observed in patients with $\mathrm{SCH}$ relative to euthyroid patients for total hypercholesterolemia, $35.9 \%$ versus $27.3 \%$, in euthyroid patients $(1.49 .95 \% \mathrm{Cl}=0.89-2.48, \mathrm{p}=0.123)$, or for $\mathrm{LDL}$ hypercholesterolemia, $64.8 \%$ versus $56.7 \%$ (1.41. $95 \%$ $\mathrm{Cl}=0.86-2.29, \mathrm{p}=0.165)$.

In multivariate analysis, it was found that the diagnosis of dyslipidemia was significantly higher in the group of patients with obesity and $\mathrm{SCH}$ (adjusted odds ratio (ORa) $3.8995 \% \mathrm{Cl} 1.39-10.90, p=0.011$ ), specifically for HDL hypocholesterolemia (ORa $2.1895 \% \mathrm{Cl} 1.22-$ $3.90, p=0.008$ ), and hypertriglyceridemia (ORa 1.80
95\% Cl1.10-2.95, $\mathrm{p}=0.018)$. All these results were adjusted for age, sex, and BMI variables (Table 3).

It was found that in addition to $\mathrm{SCH}$, dyslipidemia was significantly more frequent in those patients younger than 35 years $(\mathrm{OR} 13.51 .95 \% \mathrm{Cl}=1.79-101.689$, p 0.007) (ORa 16.35. 95\% Cl 2.15-124.28, p = 0.007). All results were adjusted for all variables described in Table 4.

\section{Discussion}

The present study shows that the prevalence of lipid disorders is higher in patients with obesity and $\mathrm{SCH}$, with an odds ratio for dyslipidemia of $3.56(95 \% \mathrm{Cl}$ : 1.29-9.84, $p=0$. 01), which differs from the results obtained by Vierhapper, where no difference was found in the lipid profiles of euthyroid and $\mathrm{SCH}$ populations ${ }^{14}$. However, this higher odds ratio for dyslipidemia is consistent with the results observed in the 10-year follow-up of Theran's cohort study, where the association between lipid profile and thyroid function 
Table 3. Dyslipidemia in patients with and without subclinical hypothyroidism

\begin{tabular}{|c|c|c|c|c|c|c|c|c|c|c|c|}
\hline & & \multicolumn{2}{|c|}{$\begin{array}{c}\text { Cases } \\
\text { sCH patients }\end{array}$} & \multicolumn{2}{|c|}{$\begin{array}{c}\text { Controls } \\
\text { Non-SCH patients }\end{array}$} & \multirow[t]{2}{*}{ OR } & \multirow[t]{2}{*}{ (CI 95\%) } & \multirow[t]{2}{*}{$\mathbf{p}$} & \multirow[t]{2}{*}{ ORa } & \multirow[t]{2}{*}{ (CI 95\%) } & \multirow[t]{2}{*}{$\mathbf{p}$} \\
\hline & & n & $\%$ & n & $\%$ & & & & & & \\
\hline \multirow[t]{2}{*}{ Dyslipidemia } & Present & 123 & 96.1 & 131 & 87.3 & 3.56 & $1.29-9.84$ & 0.011 & 3.89 & $1.39-10-90$ & 0.011 \\
\hline & Absent & 5 & 3.9 & 19 & 12.7 & & & & & & \\
\hline \multirow{2}{*}{$\begin{array}{l}\text { Total } \\
\text { Hypercholesterolemia }\end{array}$} & Present & 46 & 35.9 & 41 & 27.3 & 1.49 & $0.89-2.48$ & 0.123 & 1.44 & $0.85-2.44$ & 0.172 \\
\hline & Absent & 82 & 64.1 & 109 & 72.7 & & & & & & \\
\hline \multirow{2}{*}{$\begin{array}{l}\text { LDL } \\
\text { Hypercholesterolemia }\end{array}$} & Present & 83 & 64.8 & 85 & 56.7 & 1.41 & $0-86-2.29$ & 0.165 & 1.51 & $0.92-2.49$ & 0.101 \\
\hline & Absent & 45 & 35.2 & 63 & 43.3 & & & & & & \\
\hline \multirow{2}{*}{$\begin{array}{l}\text { HDL } \\
\text { Hypocholesterolemia }\end{array}$} & Present & 105 & 82 & 101 & 67.3 & 2.21 & $1.25-3.90$ & 0.006 & 2.18 & $1.22-3.90$ & 0.008 \\
\hline & Absent & 23 & 18 & 49 & 32.7 & & & & & & \\
\hline \multirow[t]{2}{*}{ Hypertriglyceridemia } & Present & 70 & 54.7 & 6464 & 42.7 & 1.62 & $1.00-2.60$ & 0.046 & 1.80 & $1.10-2.95$ & 0.018 \\
\hline & Absent & 58 & 45.3 & 86 & 57.3 & & & & & & \\
\hline
\end{tabular}

Cl: confidence interval; OR: Odds ratio; ORa: Odds ratio adjusted to age, sex and BMI; $\mathrm{p}$ : $\mathrm{p}$ values.

Table 4. Factors associated with dyslipidemia in multiple regression analysis

\begin{tabular}{|c|c|c|c|c|c|c|c|c|c|c|c|}
\hline & & \multicolumn{2}{|c|}{$\begin{array}{l}\text { Dyslipidemia } \\
\text { Cases }\end{array}$} & \multicolumn{2}{|c|}{$\begin{array}{l}\text { Non-dyslipidemic } \\
\text { controls }\end{array}$} & \multirow[t]{2}{*}{$\mathbf{O R}$} & \multirow[t]{2}{*}{ (CI 95\%) } & \multirow[t]{2}{*}{ p } & \multirow[t]{2}{*}{ ORa } & \multirow[t]{2}{*}{ (CI 95\%) } & \multirow[t]{2}{*}{ p } \\
\hline & & $\mathbf{n}$ & $\%$ & n & $\%$ & & & & & & \\
\hline \multirow[t]{2}{*}{ Sex } & Females & 207 & 91.2 & 20 & 8.8 & 0.88 & $0.28-2.69$ & 0.824 & 0.78 & $0.24-2.55$ & 0.690 \\
\hline & Males & 47 & 92.2 & 4 & 7.8 & & & & & & \\
\hline \multirow[t]{2}{*}{ Age } & $\leq 35$ years & 94 & 98.9 & 1 & 1.1 & 13.51 & $1.79-101.68$ & 0.011 & 16.35 & $2.15-124.28$ & 0.007 \\
\hline & $\geq 35$ years & 160 & 87.4 & 23 & 12.6 & & & & & & \\
\hline \multirow[t]{2}{*}{ Body mass index } & $\begin{array}{l}\text { Obesity Grade I } \\
\text { and II (BMI } \leq 40)\end{array}$ & 89 & 90.8 & 9 & 9.2 & 0.90 & $0.38-2.15$ & 0.820 & 1.06 & $0.42-2.66$ & 0.894 \\
\hline & $\begin{array}{l}\text { Obesity Grade III } \\
\text { (BMI } \geq 40)\end{array}$ & 164 & 91.6 & 15 & 8.4 & & & & & & \\
\hline \multirow{2}{*}{$\begin{array}{l}\text { Subclinical } \\
\text { hypothyroidism }\end{array}$} & Present & 123 & 96.1 & 5 & 3.9 & 3.56 & $1.29-9.84$ & 0.014 & 4.50 & $1.58-12.77$ & 0.005 \\
\hline & Absent & 131 & 87.3 & 19 & 12.7 & & & & & & \\
\hline
\end{tabular}

Cl: confidence interval; OR: Odds ratio; ORa: Odds ratio adjusted to age, sex and BMI; $\mathrm{p}$ : $\mathrm{p}$ values.

was evident and favorable lipid profile trends were found after adjusting for the thyroid status in patients with $\mathrm{SCH}$. That includes significant decreases in the levels of all lipids except HDL-C. This means that alterations in the lipid profile may be transient in relation to the time of evolution and thyroid status of $\mathrm{SCH}$, showing a downward trend in relation to the 10-year follow-up of patients and the recovery of normal thyroid function ${ }^{15}$.

Although the relationship between lipid profile and $\mathrm{SCH}$ has been reported in numerous studies, the results regarding different dyslipidemias have been contradictory. Vierhapper, based on analysis of the lipid profile in patients with $\mathrm{SCH}$ in Austria, found no 
difference in total cholesterol (TC), LDL-C, HDL-C, and TG concentrations in relation to the euthyroid population $^{14}$. Canaris reported increased TC and LDL-C concentrations in patients with $\mathrm{SCH}^{2}$.

Xiao-Li, based on the meta-analysis of 16 studies, showed that the population with $\mathrm{SCH}$ showed an increase in the concentrations of TC, LDL-C, and TG, with the weighted mean difference being $12.17 \mathrm{mg} / \mathrm{dl}$, $7.01 \mathrm{mg} / \mathrm{dl}$, and $13.19 \mathrm{mg} / \mathrm{dl}$, respectively $(p<0.001$ for all), with no significant differences in $\mathrm{HDL}-\mathrm{C}^{16}$.

According to the conclusions gathered from the EPIC-Norfolk cohort study, Boekholdt et al. showed that there is a positive relationship between thyroid abnormalities and an altered cardiovascular risk profile. High levels of TSH were associated with increased plasma concentration of TC, LDL-C, and TG, and the results depended on the age and sex distribution of the study population, with alterations being more frequent among women with $\mathrm{SCH}^{17}$.

Unlike the results reported by Garduño-García et al. ${ }^{18}$, who showed that TC concentrations were significantly higher in Mexican population with $\mathrm{SCH}$ than in euthyroid patients $(213.07 \mathrm{mg} / \mathrm{dl}$ vs. $206.5 \mathrm{mg} / \mathrm{dl}$, respectively), estimating the relative risk (RR) for development of age- and sex-adjusted hypercholesterolemia at 1.35 (95\% Cl: 1.06-1.70, $\mathrm{p}<0.032)^{17}$, our study showed an increase in HDL hypocholesterolemia and hypertriglyceridemia in patients with $\mathrm{SCH}$ versus euthyroid patients. The odds ratio was estimated at $2.21(95 \% \mathrm{Cl}$ : 1.25-3.9, $\mathrm{p}=0.005)$ and $1.62(95 \% \mathrm{Cl}: 1-2.6, \mathrm{p}=0$. 046), respectively. These results can explain that since $\mathrm{SCH}$ is not the only risk factor for the development of dyslipidemia in our study population, being another risk factor the obesity, it generates a decrease in the triglyceride lipolysis and an alteration of the peripheral uptake of free fatty acids. Furthermore, it involves an increase in fatty acids flow with LDL-C formation. The positive correlation between TSH levels, total cholesterol, and triglyceride levels, observed by Garduño et al., could also be an explanation for obesity, since an increase in TSH levels could be interpreted as an adaptation mechanism against weight gain in morbidly obese patients.

Similarly to the results presented in the EPIC-Norfolk cohort study ${ }^{17}$, an increase in TG was documented in the population with $\mathrm{SCH}$, with a predominance of female patients. This is consistent with the data obtained in our study with $81.7 \%$ being female patients.
The results of the Colorado study ${ }^{2}$ show an increase in TC and LDL-C concentrations when comparing the lipid profiles of American patients in 2000. Our study differs from the aforementioned study because, despite an increase in TC and LDL-C was found in the population with $\mathrm{SCH}, p$-values do not denote statistical significance ( $p=0.123$ and $p=0.165$, respectively). It is worth mentioning that the Colorado study inclusion criteria currently differ from the diagnostic criteria for $\mathrm{SCH}$, taking $5.1 \mathrm{mU} / \mathrm{L}$ as the maximum TSH value, in contrast with the values suggested by the American Thyroid Association (ATA) $2012^{19}$ and ETA $2013^{1}$.

One of the deficiencies of our study is the lack of anti-TPO antibody measurements, which is a characteristic that should be highlighted, since they are associated with $\mathrm{SCH}$ in $60-80 \%$ of cases $^{20,21}$. This also includes a single measurement of serum thyroid hormone levels, as there are different factors such as age, $\mathrm{BMI}$, and the circadian cycle, which are associated with fluctuations in the thyroid hormone profile ${ }^{22}$.

\section{Conclusions}

The relationship between $\mathrm{SCH}$ and dyslipidemia has been analyzed with controversial results at the international level. In the Mexican population of our study, that is, patients with obesity, $\mathrm{SCH}$ is a risk factor for the development of dyslipidemia, specifically hypertriglyceridemia and HDL hypocholesterolemia. At present, the benefits and criteria have not been clearly defined for the initiation of levothyroxine replacement therapy in this population, given the heterogeneity of the results, regarding its impact on the lipid profile of patients with $\mathrm{SCH}$, despite suggesting a potential benefit of the use of levothyroxine in relation to dyslipidemias and obesity.

\section{Conflicts of interest}

The authors declare have no conflicts of interest.

\section{Ethical disclosures}

Protection of human and animal subjects. The authors declare that no experiments were performed on humans or animals for this study.

Confidentiality of data. The authors declare that they have followed the protocols of their work center on the publication of patient data. 
Right to privacy and informed consent. The authors declare that no patient data appear in this article.

\section{References}

1. Pearce SH, Brabant G, Duntas LH, Monzani F, Peeters RP, Razvi S et al. 2013 ETA guideline: management of subclinical hypothyroidism. Eur Thyroid J. 2013;2:215-28.

2. Canaris GJ, Manowitz NR, Mayor G, Ridgway EC. The Colorado thyroid disease prevalence study. Arch Intern Med. 2000;160:526-34.

3. Vanderpump MP, Tunbridge WM, French JM, Appleton D, Bates D, Clark F, et al. The incidence of thyroid disorders in the community: a twenty-year follow-up of the Whickham Survey. Clin Endocrinol (Oxf). 1995;43:55-68.

4. Krotkiewski M. Thyroid hormones in the pathogenesis and treatment of obesity. Eur J Pharmacol. 2002;440:85-98.

5. Longhi S, Radetti G. Thyroid function and obesity. J Clin Res Pediatr Endocrinol. 2013;5:40-4.

6. Biondi B. Thyroid and obesity: an intriguing relationship. J Clin Endocrinol Metab. 2010;95:3614-7.

7. Moulin de Moraes CM, Mancini MC, de Melo ME, Figueiredo DA, Villares SM, Rascovski A, et al. Prevalence of subclinical hypothyroidism in a morbidly obese population and improvement after weight loss induced by Roux-en-Y gastric bypass. Obes Surg. 2005;15:1287-91.

8. Kitahara CM, Platz EA, Ladenson PW, Mondul AM, Menke A, Berrington de González A. Body fatness and markers of thyroid function among U.S. men and women. PLoS One. 2012;7:e34979.

9. Montoya-Morales DS, Tapia-González MA, Alamilla-Lugo L, Sosa-Caballero A, Muñoz-Solís A. Jiménez-Sánchez M. Alteraciones de la función tiroidea en pacientes con obesidad mórbida. Rev Med Inst Mex Seguro Soc. 2015;53 Supl 1:S18-22.

10. Pearce E. Update in lipid alterations in subclinical hypothyroidism. J Clin Endocrinol Metab. 2012;97:326-33.

11. Klop B, Elte JW, Cabezas MC. Dyslipidemia in obesity: mechanisms and potential targets. Nutrients. 2013;5:1218-40.
12. ENSANUT. Informe de Resultados de la Encuesta Nacional de Salud y Nutrición 2018. Presentación de Resultados; [diapositiva 41]. Available from: https://www.ensanut.insp.mx/encuestas/ensanut2018/informes. php. [Last accesssed on 2020 Jul 15].

13. Garvey WT, Mechanick JI, Brett EM, Garber AJ, Hurley DL, Jastreboff AM, et al. American Association of Clinical Endocrinologists and American College of Endocrinology comprehensive clinical practice guidelines for medical care of patients with obesity. Endocr Pract. 2016;22 Suppl 3:1-203.

14. Vierhapper H, Nardi A, Grösser P, Raber W, Gessl A. Low-density lipoprotein cholesterol in subclinical hypothyroidism. Thyroid. 2000;10:981-4

15. Ahl S, Amouzegar A, Gharibzadeh S, Delshad H, Tohidi, Azizi F. Trend of lipid and thyroid function tests in adults without overt thyroid diseases: a cohort from Tehran thyroid study. PLoS One. 2019;14:e0216389.

16. Liu XL, He S, Zhang SF, Wang J, Sun XF, Gong CM, et al. Alteration of lipid profile in subclinical hypothyroidism: a meta-analysis. Med Sci Monit. 2014;20:1432-41.

17. Boekholdt SM, Titan SM, Wiersinga WM, Chatterjee K, Basart DC Luben R, et al. Initial thyroid status and cardiovascular risk factors: the EPIC-Norfolk prospective population study. Clin Endocrinol (Oxf). 2010;72:404-10.

18. Garduño-García JJ, Alvirde-Garcia U, López-Carrasco G, Padilla Mendoza ME, Mehta R, Arellano-Campos O, et al. TSH and free thyroxine concentrations are associated with differing metabolic markers in euthyroid subjects. Eur J Endocrinol. 2010;163:273-8.

19. Garber JR, Cobin RH, Gharib H, Hennessey JV, Klein I, Mechanick JI, et al. Clinical practice guidelines for hypothyroidism in adults: cosponsored by the American Association of Clinical Endocrinologists and the American Thyroid Association. Endocr Pract. 2012;18:988-1028.

20. Somwaru LL, Arnold AM, Joshi N, Fried LP, Cappola AR. High frequency of and factors associated with thyroid hormone over-replacement and under-replacement in men and women aged 65 and over. J Clin Endocrinol Metab. 2009;94:1342-5.

21. Hollowell JG, Staehling NW, Flanders WD, Hannon WH, Gunter EW, Spencer CA, et al. Serum TSH, T(4), and thyroid antibodies in the United States population (1988 to 1994): national health and nutrition examination survey (NHANES III) J Clin Endocrinol Metab. 2002;87:489-99.

22. Bremner AP, Feddema P, Leedman PJ, Brown SJ, Beilby JP, Lim EM, et al. Age-related changes in thyroid function: a longitudinal study of a community-based cohort. J Clin Endocrinol Metab. 2012;97:1554-62. 